\title{
LAS TIC EN LA CONSTRUCCION DEL ESPACIO EUROPEO DE EDUCACIÓN SUPERIOR. DOS EXPERIENCIAS DOCENTES EN TEORÍA ECONÓMICA
}

\author{
Amparo Carrasco Pradas, Esperanza Gracia Expósito y Covadonga de la Iglesia Villasol \\ Universidad Complutense de Madrid, España
}

\section{LA UNIVERSIDAD ESPAÑOLA EN EL MARCO DEL ESPACIO EUROPEO DE EDUCACIÓN SUPERIOR (EEES): LAS TIC COMO MOTOR DEL CAMBIO}

La Universidad Española en su conjunto está sumida en un proceso de cambio estructural, sustentado en un pilar, el establecimiento de una Europa del conocimiento, que determina dos retos y un único destino: la mejora en la calidad de la enseñanza superior. En concreto, tales retos son: 1) El despegue en la carrera institucional de las distintas Universidades y Facultades por obtener la acreditación de las titulaciones que imparten y la obtención de la mención de excelencia ${ }^{1}$, 2) las declaraciones de la Sorbona (1998) y de Bolonia (1999), ratificadas por 32 países en el comunicado de Praga (2001), con el horizonte temporal del año 2010, para completar e proceso de convergencia en el Espacio Europeo de Educación Superior, en un proceso que debe ir mucho más allá de la mera definición y cómputo de los créditos ECTS (European Credit Transfer System). La armonización propuesta exige, de hecho, una profunda transformación del modelo educativo, que ponga el énfasis en el propio proceso de enseñanzaaprendizaje, lo cual pasa por una atención individualizada que permita cuantificar el grado de esfuerzo del alumno.

La adhesión de la Universidad española a este proceso de convergencia no es una mera declaración de intenciones, habiéndose concretado ya desde un punto de vista legislativo en dos Reales Decretos que regulan el sistema europeo de créditos y calificaciones en las titulaciones universitarias oficiales y el procedimiento para la expedición del Suplemento Europeo al Título².

La incorporación de las nuevas tecnologías de información y comunicación (TIC) a la metodología docente universitaria entendemos es imprescindible para acometer el reto de construir una Europa del conocimiento basada en un sistema educativo de calidad. No obstante, la generalización en el uso de las TIC no garantiza por sí sola la consecución de los objetivos perseguidos y es, por tanto, una condición necesaria pero no suficiente. Antes bien, dicha consecución pasa ineludiblemente por una profunda transformación de los fundamentos pedagógicos del sistema de enseñanza universitaria.

La conjunción del desarrollo del EEES y la incorporación y extensión del uso de las TIC debe facilitar la inexcusable reformulación del papel y práctica pedagógica del docente, orientada hacia el pretendido desarrollo de las destrezas y potencialidades cognitivas del alumno. En este sentido, las TIC

\footnotetext{
${ }^{1}$ Propiciada por la aprobación y puesta en marcha de la ANECA, Agencia Nacional de Evaluación, Calidad y Acreditación, creada por el MECD, en cumplimiento de lo establecido en el artículo 32 de la Ley de Universidades (Ley Orgánica 6/2001, de 21 de diciembre), cuyas funciones, definidas en el articulo 31.3 de la referida Ley, son las de contribuir a medir y hacer público el rendimiento de la Educación Superior, y reforzar la transparencia y comparabilidad de nuestro sistema universitario.

${ }^{2}$ RD 1125/2005, de 5 de septiembre, y RD 1044/2005, de 1 de agosto.
} 
facilitan el desarrollo de una acción formativa flexible, centrada en el estudiante y adaptada a sus características y necesidades, con un seguimiento individualizado y continuo de los alumnos.

De cualquier forma, el éxito de las TIC en la enseñanza superior requiere, no solo una apuesta decidida desde el punto de vista institucional, sino además un incuestionable esfuerzo de adaptación por parte del profesorado y del alumnado a los nuevos modos de aprendizaje.

\section{NUESTRA EXPERIENCIA DOCENTE EN TEORIA ECONÓMICA}

Las experiencias docentes cuyos resultados se presentarán en este trabajo, se enmarcan en la estrategia de mejora de la calidad emprendida por la universidad española. En concreto, los dos proyectos de innovación educativa (PIE) y el diseño y puesta en marcha de tres cursos con la plataforma digital WebcT dentro del campus virtual, impulsados por la UCM como apoyo a la docencia presencial ${ }^{3}$, son consistentes con el espíritu que inspira los acuerdos de Bolonia.

Pese a las necesarias reservas a la hora de obtener conclusiones extrapolables con carácter general, dadas las limitaciones en cuanto a la representatividad muestral y el carácter experimental de las iniciativas, los resultados apuntan claramente a que la utilización de las TIC permite un seguimiento individualizado y aumenta la motivación del alumno, aspecto fundamental en el proceso formativo, al tiempo que mejora sus resultados.

El origen de los dos proyectos de innovación educativa está en la necesidad de mejorar, ampliar y armonizar el material didáctico del área de Microeconomía ${ }^{4}$, con el fin de facilitar la asimilación de dichos contenidos por parte de los alumnos, y paliar las dificultades que a este respecto señalan reiteradamente nuestros estudiantes en las encuestas de evaluación docente disponibles.

Estos proyectos han permitido generar un material didáctico en versión electrónica, disponible en la red en ambos casos, y en una versión local en CD ROM en el PIE epolitic ${ }^{5}$. Como valor añadido fundamental, todos ellos incorporan un tutor o asistente electrónico y un simulador de pruebas.

Con respecto al tutor virtual, su inclusión responde a un objetivo de proporcionar a los alumnos un marco conceptual que les permita abordar la resolución de los múltiples y diversos problemas con los que sin duda se enfrentarán en su desarrollo profesional. La consecución de este ambicioso objetivo pasa necesariamente por el uso de un método de aprendizaje que desarrolle el tipo de procesos cognitivos conducentes no sólo al correcto planteamiento analítico de los problemas, sino a aprovechar el potencial didáctico que aportan sus propios errores. En este sentido, las cuestiones test del material han sido diseñadas dando, al menos, tanta importancia a la respuesta correcta como a las erróneas, que inciden en los fallos conceptuales que sistemáticamente cometen los alumnos. De hecho, estos fallos reflejan carencias en los esquemas lógicos previamente adquiridos por los estudiantes y su limitada capacidad de abstracción. Con este método didáctico se pretende corregir estas deficiencias y que el entrenamiento

\footnotetext{
${ }^{3}$ Los contenidos de estas iniciativas se pueden consultar en http://www.ucm.es/info/microint, http://www.ucm.es/info/epolitic y http://alfama.sim.ucm.es/campusvirtual.

${ }^{4}$ Concretamente, nos referimos a las asignaturas de Microeconomía I y II de la Licenciatura de Economía (LECO), de Microeconomía de la Licenciatura de Administración y Dirección de Empresas (LADE) y de Microeconomía y Economía Política (Introducción a la Economía) de la Diplomatura de Empresariales, que constituyen materias troncales dentro de sus respectivos planes de estudio.

${ }^{5}$ Si resultara de interés, se puede acceder durante la presentación al material didáctico de los PIE, tanto online como a la versión local, ligeramente diferente por contener animaciones no incluidas en la versión para la web.
} 
aplicado a problemas concretos del ámbito económico genere sinergias para afrontar con éxito los desafíos tanto del aprendizaje continuo a lo largo de su vida como los del propio desarrollo profesional.

El funcionamiento del tutor electrónico en las aplicaciones diseñadas conjuga la sencillez en el manejo con un tratamiento completo del problema abordado. El alumno, cuado accede a un ejercicio, dispone de cuatro opciones con una única correcta y, cuando elige una de ellas, en el caso de ser errónea el tutor explica las causas de dicho error. El estudiante puede aprender de dicho error, volver atrás, elegir otra respuesta, con la posibilidad de volver a equivocarse hasta dos veces más. Esta posibilidad de iteración que ofrece el programa permite que la mayor parte de los alumnos se enfrente a los errores sistemáticos que nuestra experiencia, básicamente asociada al proceso de evaluación, nos ha permitido detectar de forma continuada. Es precisamente la dramática persistencia de estos errores conceptuales el origen de nuestro esfuerzo didáctico, que ha exigido su identificación y sistematización, y que se ha materializado en los proyectos de innovación educativa realizados. Lógicamente, también la respuesta correcta desarrolla una explicación detallada de los razonamientos que la justifican.

Ejercicio P.I.E. epolitic

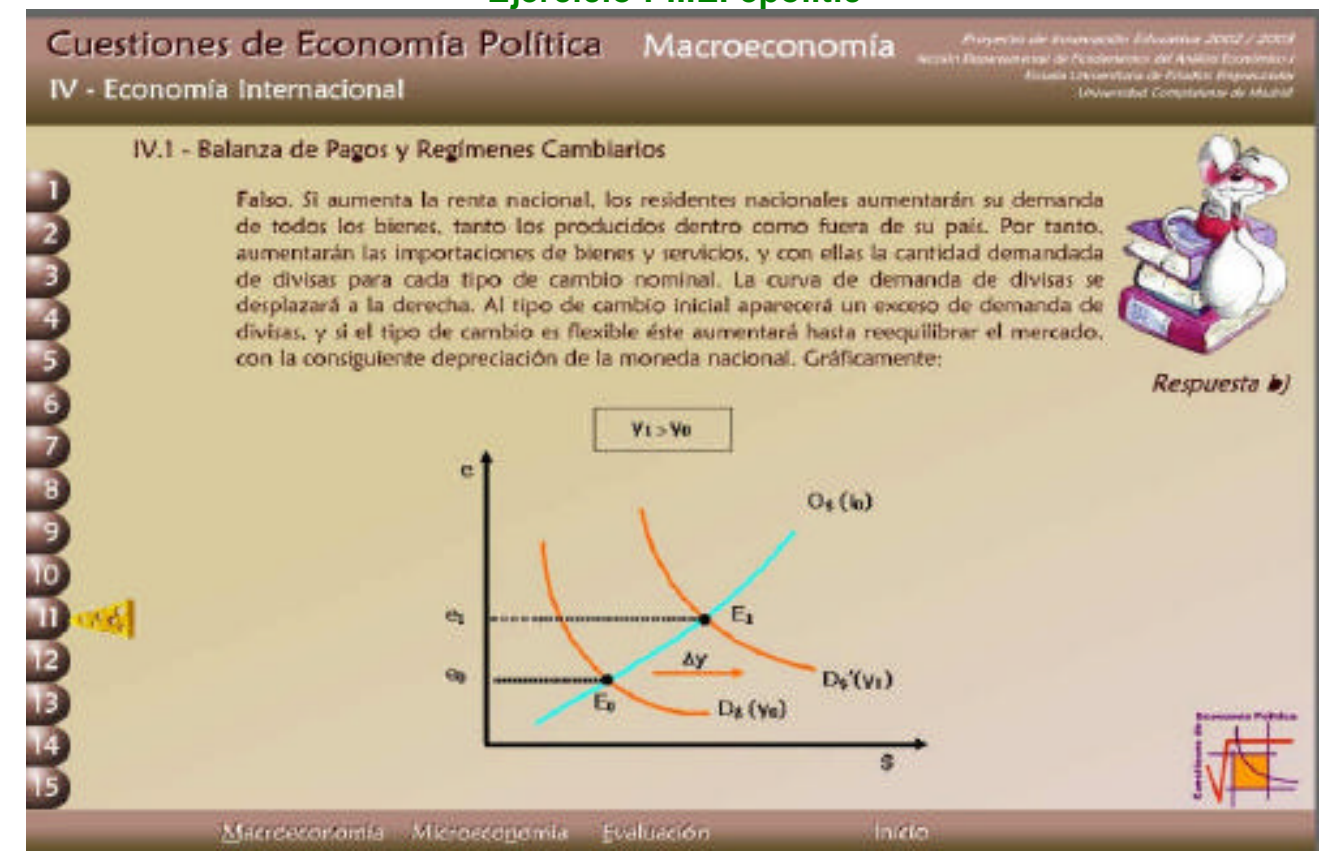


Ejercicio P.I.E. microint

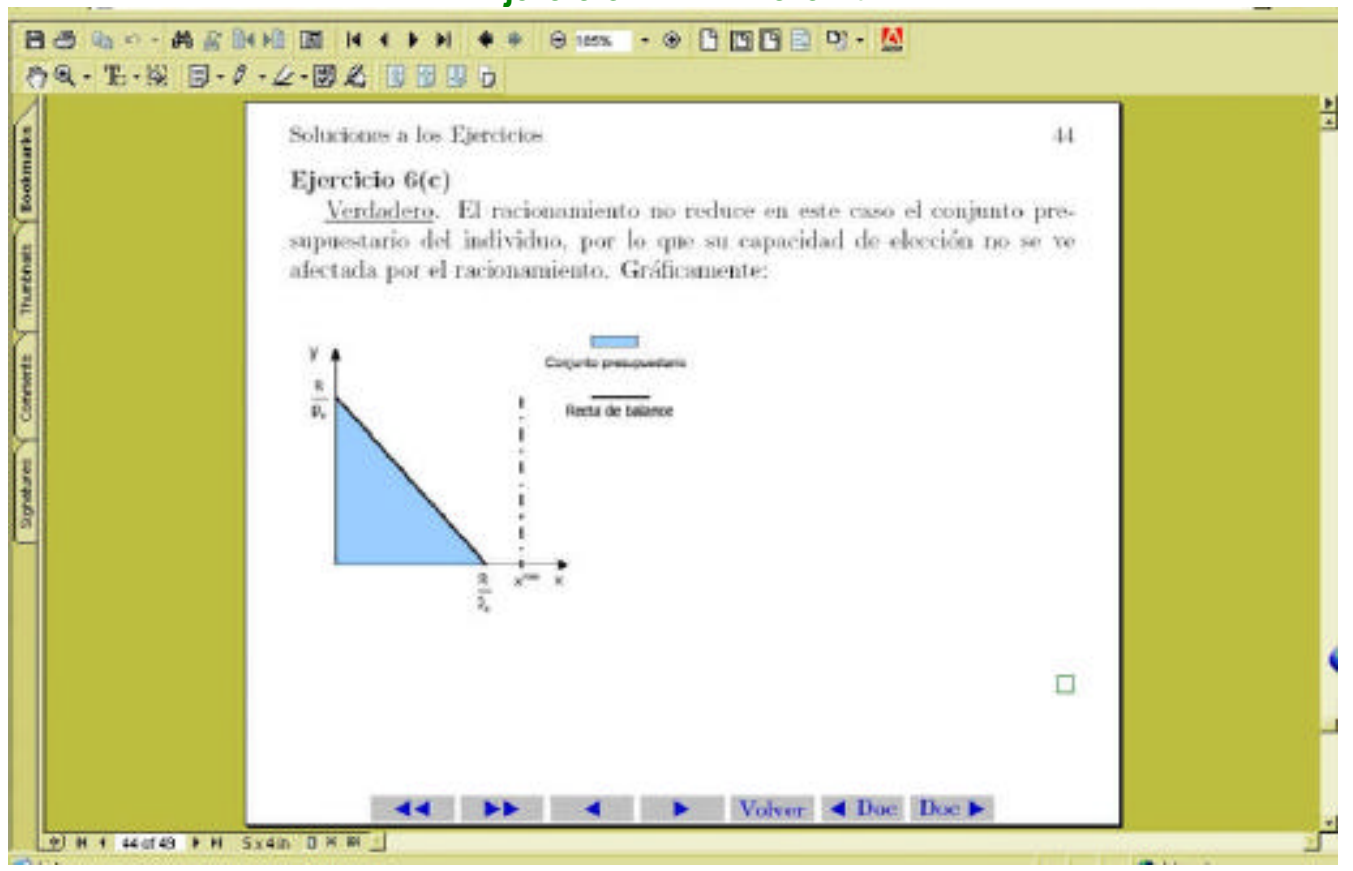

En lo que se refiere al simulador de pruebas, permite al alumno no sólo contrastar su adecuada progresión en el conocimiento de la materia en cuestión sino, también, disponer de una señal del nivel y la manera en que dichos conocimientos serán exigidos, permitiéndole orientar adecuadamente su estudio. Con este mecanismo, el estudiante puede detectar lo que sabe y, lo que es más importante, aquello que no sabe. Saber qué sabe constituye un estímulo para el alumno, que le motiva y refuerza en su estrategia. Saber lo que no sabe, es primordial para reorientar su método de estudio y, todo ello además, en un momento en el que dicha información es relevante para continuar su proceso de aprendizaje y culminarlo con éxito.

En concreto, las aplicaciones diseñadas son versátiles, permitiendo que los alumnos autoevalúen sus conocimientos tanto de forma global, como en función de otros criterios, como capítulos, bloques temáticos y asignaturas. Esta posibilidad de control parcial de los conocimientos potencia las bondades, ya señaladas, del proceso de autoevaluación. 
Simulador examen P.I.E. microint

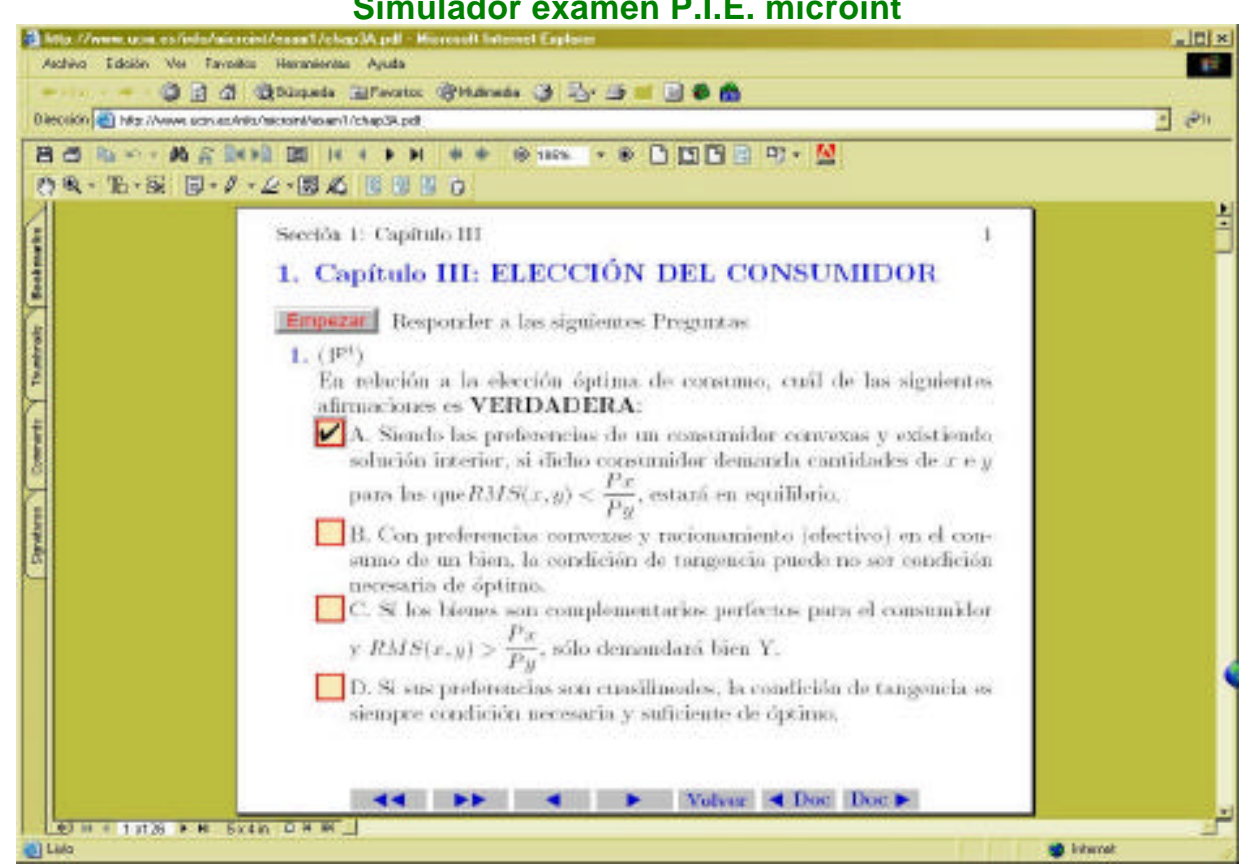

Simulador examen P.I.E. epolitic

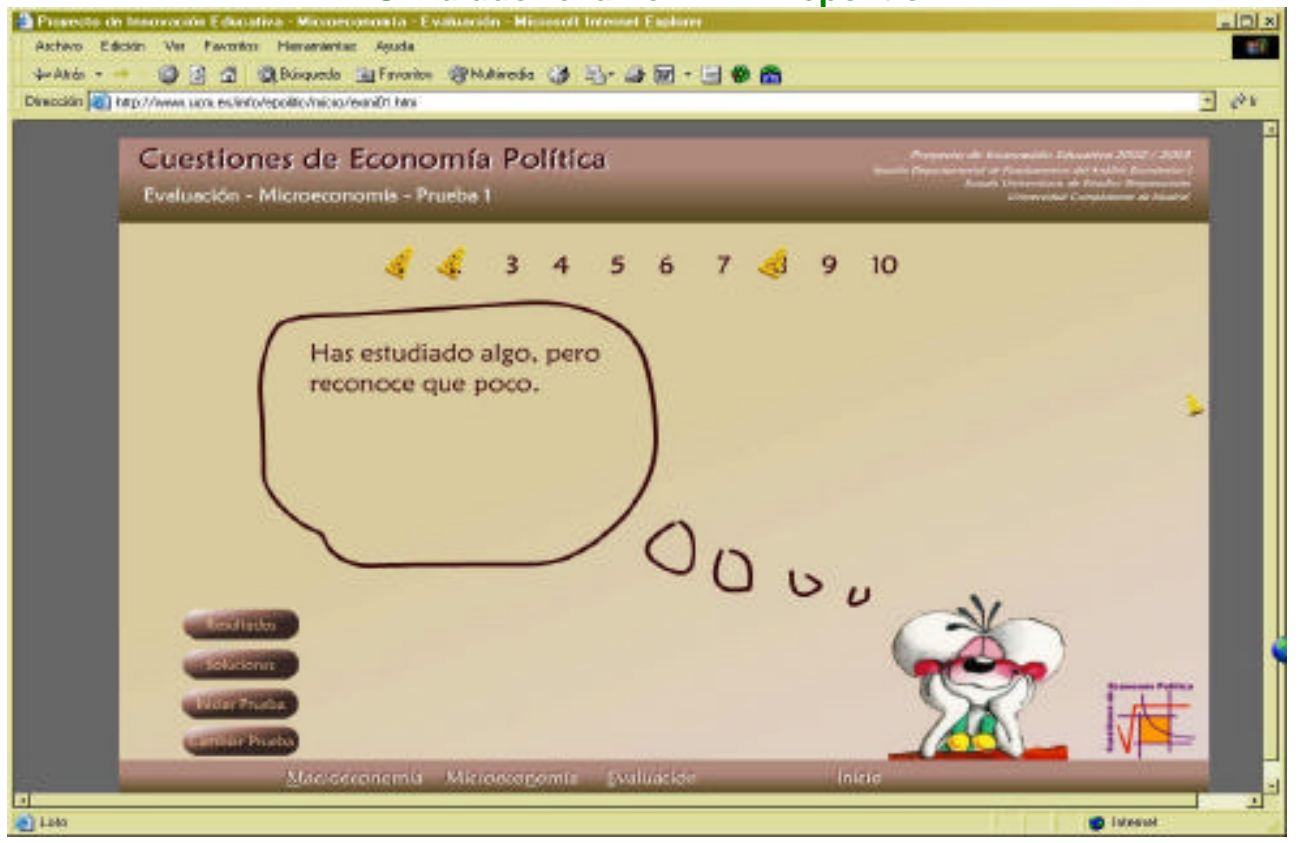

La estrategia didáctica descrita, tutor virtual y simulador de pruebas, persigue favorecer la autonomía del estudiante universitario, aspecto éste prioritario en el nuevo entorno de aprendizaje consistente con el espíritu del EEES. Además y en esta línea, los PIE han ido dirigidos también a facilitar el intercambio de información entre alumnos y profesores, a través de un buzón de sugerencias, con el objetivo de paliar una de las deficiencias de los sistemas tradicionales de enseñanza reiteradamente denunciadas, la unidireccionalidad de los flujos de información.

Tras un curso de funcionamiento en dos de los PIES, se dispone de información estadística relativa a aspectos como el número de entradas, su procedencia por países, distribución por franjas horarias, por días de la semana, por semanas y meses, por servidor, etc. Aunque una valoración de los datos no puede ser concluyente, por razones obvias (sólo se dispone un cross-section para el curso actual, ausencia de ciertas variables relevantes y sobre las cuales esperamos poder obtener información en un futuro próximo), 
a continuación se presenta parte de la información disponible. Si bien cabía esperar cierta estacionalidad en el acceso de los estudiantes al material en torno al período de exámenes, sí queremos destacar la extremada concentración en las entradas durante las dos semanas previas al período oficial de exámenes. Como mínimo, este resultado debería hacernos reflexionar sobre cómo podemos motivar a nuestros estudiantes para una distribución más racional y continuada de su esfuerzo en una materia como la teoría económica que exige una asimilación gradual de los conocimientos.

Distribución entradas PIE por procedencia geográfica

Continente de origen

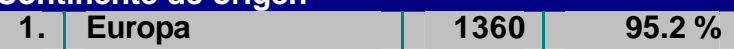

2. Centroamérica

3. Sudamérica

4. EEUU y Canadá

5. Asia

Desconocido

Total

$1.3 \%$

$1.0 \%$

$0.1 \%$

$0.1 \%$

$2.2 \%$

\begin{tabular}{r|r}
32 & $2.2 \%$ \\
1429 & $100.0 \%$ \\
\hline
\end{tabular}

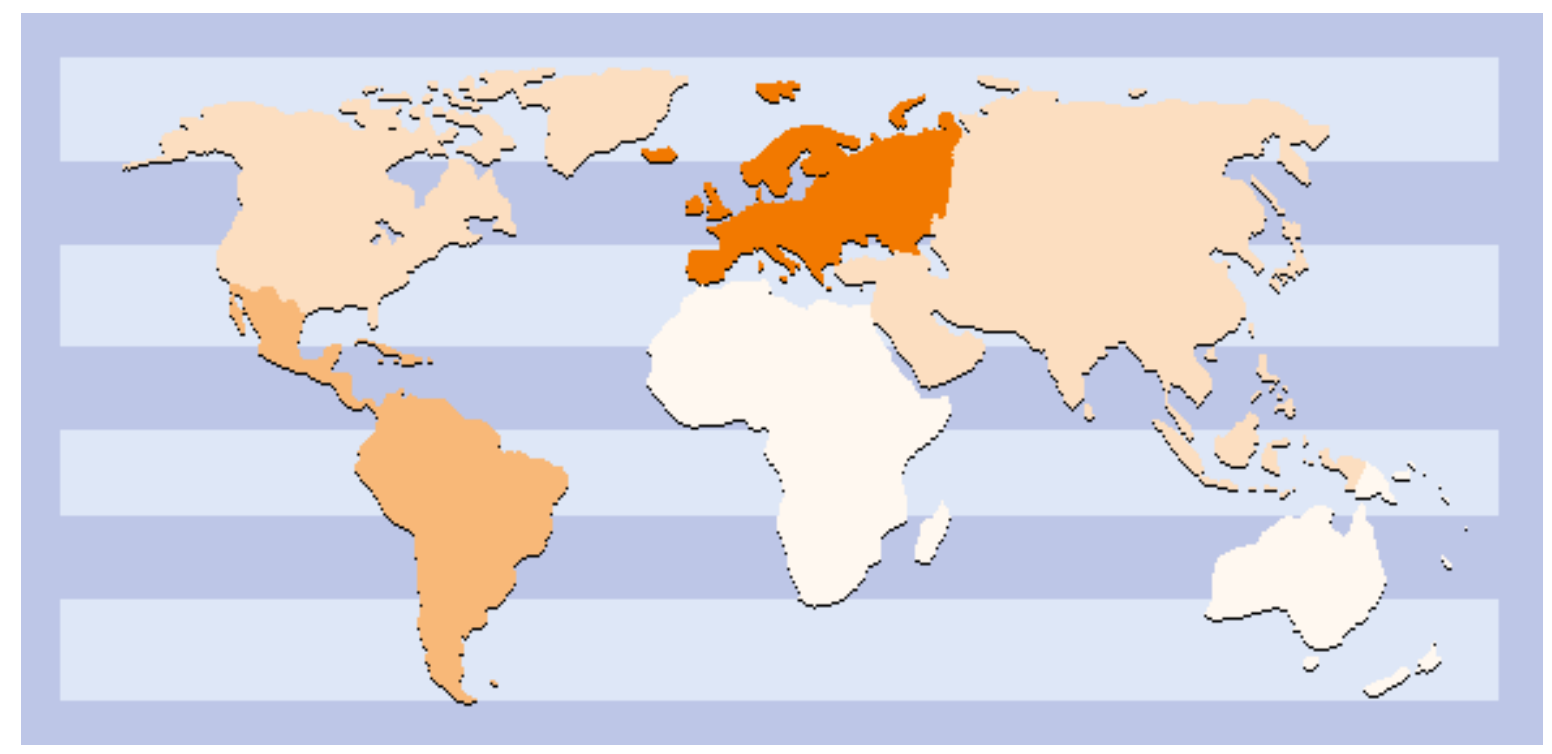

Distribución entradas PIE por días de la semana

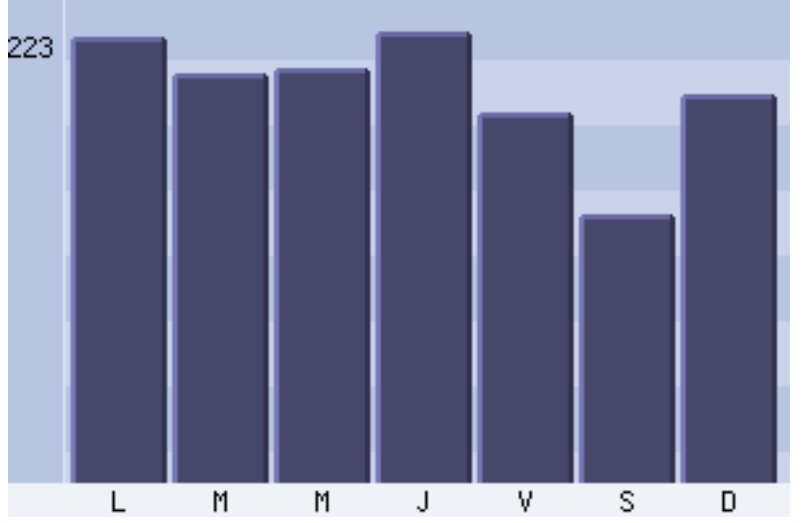




\section{Distribución entradas PIE por horas}

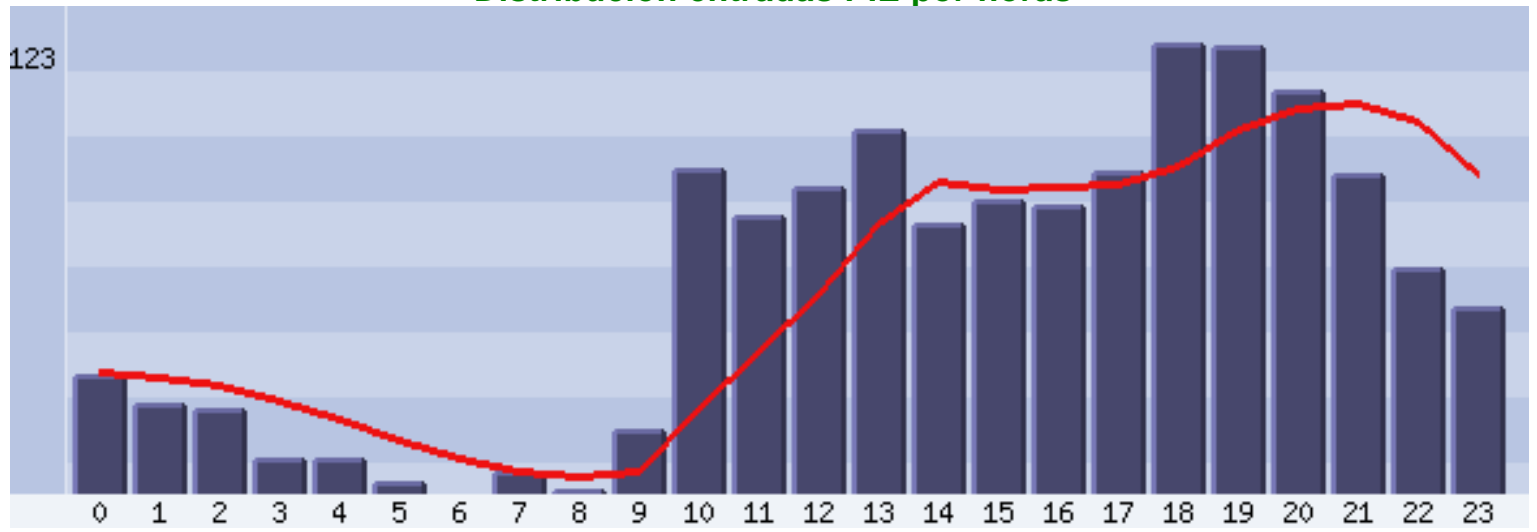

Distribución entradas PIE por semanas

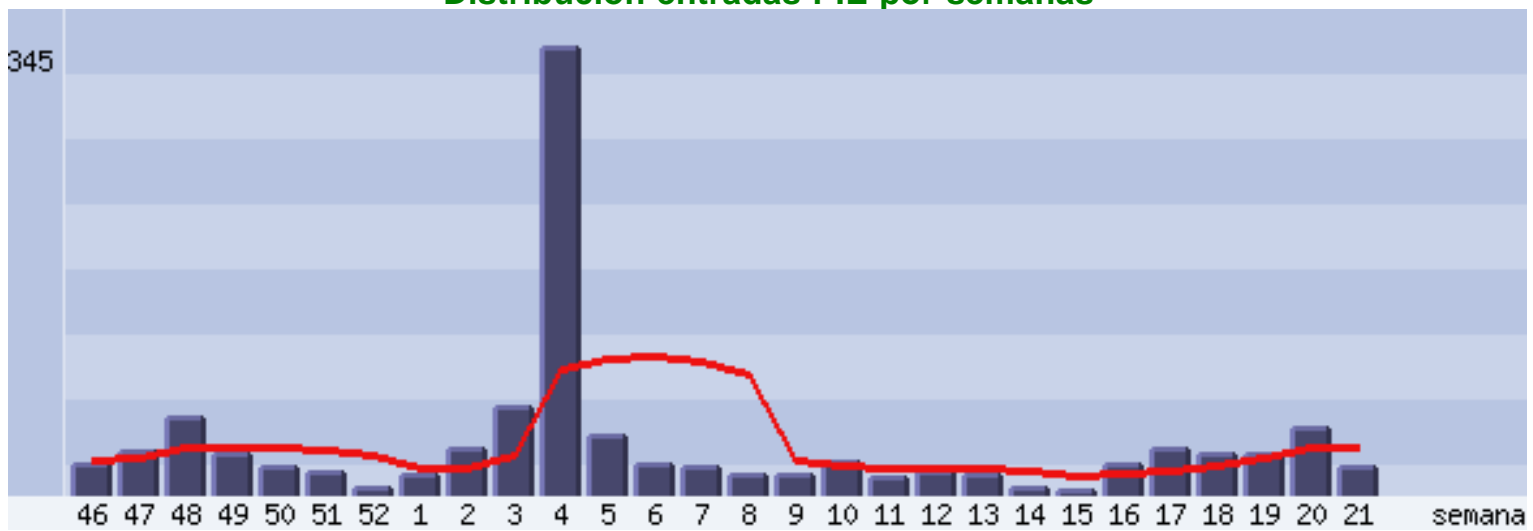

\section{Distribución entradas PIE por meses}

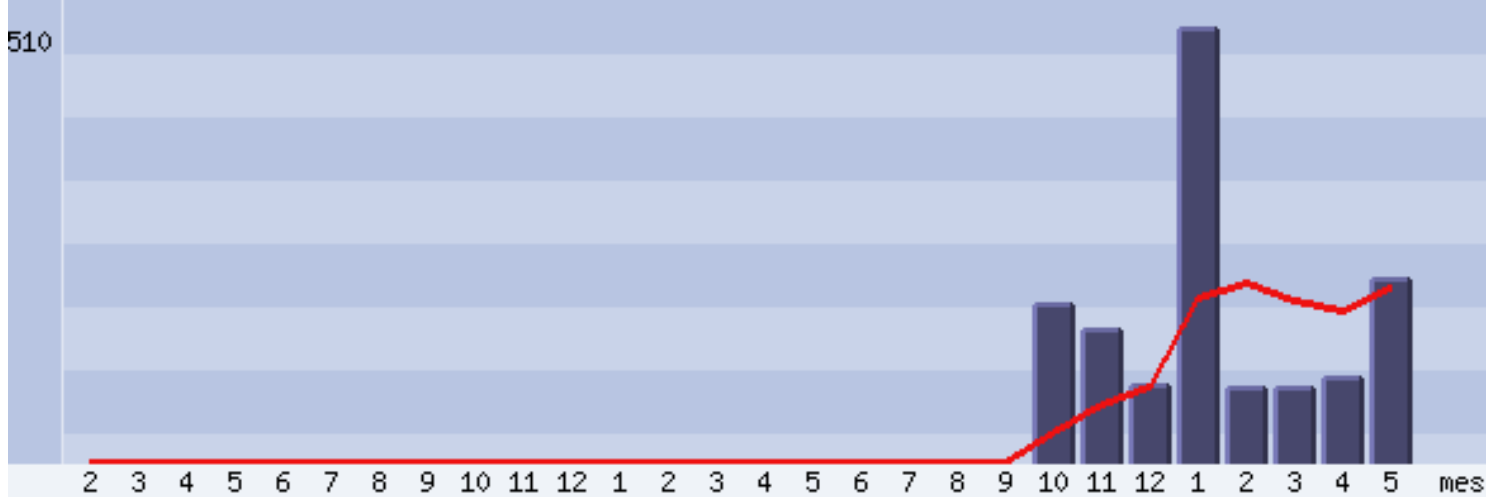

En lo que respecta a la iniciativa de incorporación al campus virtual, como apoyo a la docencia presencial, nuestra participación está consistiendo en el diseño y aplicación durante el curso académico 2003-04 de un curso de Microeconomía Intermedia, uno de Economía Política (ambos para la Diplomatura de Estudios Empresariales) y uno de Microeconomía Superior (Licenciatura en Economía), y en la colaboración en las tareas de coordinación y puesta en marcha del proyecto piloto. Dado su carácter experimental, esta iniciativa está siendo restringida a un número muy limitado de asignaturas, de profesores y de alumnos. Así, han participado 50 alumnos en cada una de las asignaturas de la Diplomatura, seleccionados estrictamente por el orden de llegada, y 145 alumnos para la asignatura de Microeconomía Superior II, que corresponden al total de las solicitudes.

Dado que la participación en el campus virtual comparte objetivos y estrategia didáctica con el desarrollo de los PIE, instrumentos ambos que persiguen facilitar una nueva manera de enseñanza- 
aprendizaje acorde con el espíritu del EEES, no vamos a insistir en lo ya señalado, sino que nos centraremos en concretar el contenido de los cursos desarrollados y los resultados estadísticos correspondientes a la evaluación docente realizada por los alumnos.

La plataforma digital utilizada ha sido WebCT y el diseño de los cursos ha incluido la programación, realización de contenidos y ejercicios de autoevaluación, planificación de trabajos, realización de exámenes que forman parte de la evaluación continuada del alumno, utilización de herramientas de comunicación asincrónica (avisos, foros de debate y correo electrónico) y tutorización personalizada.

\section{Menú Curso Economía Política}

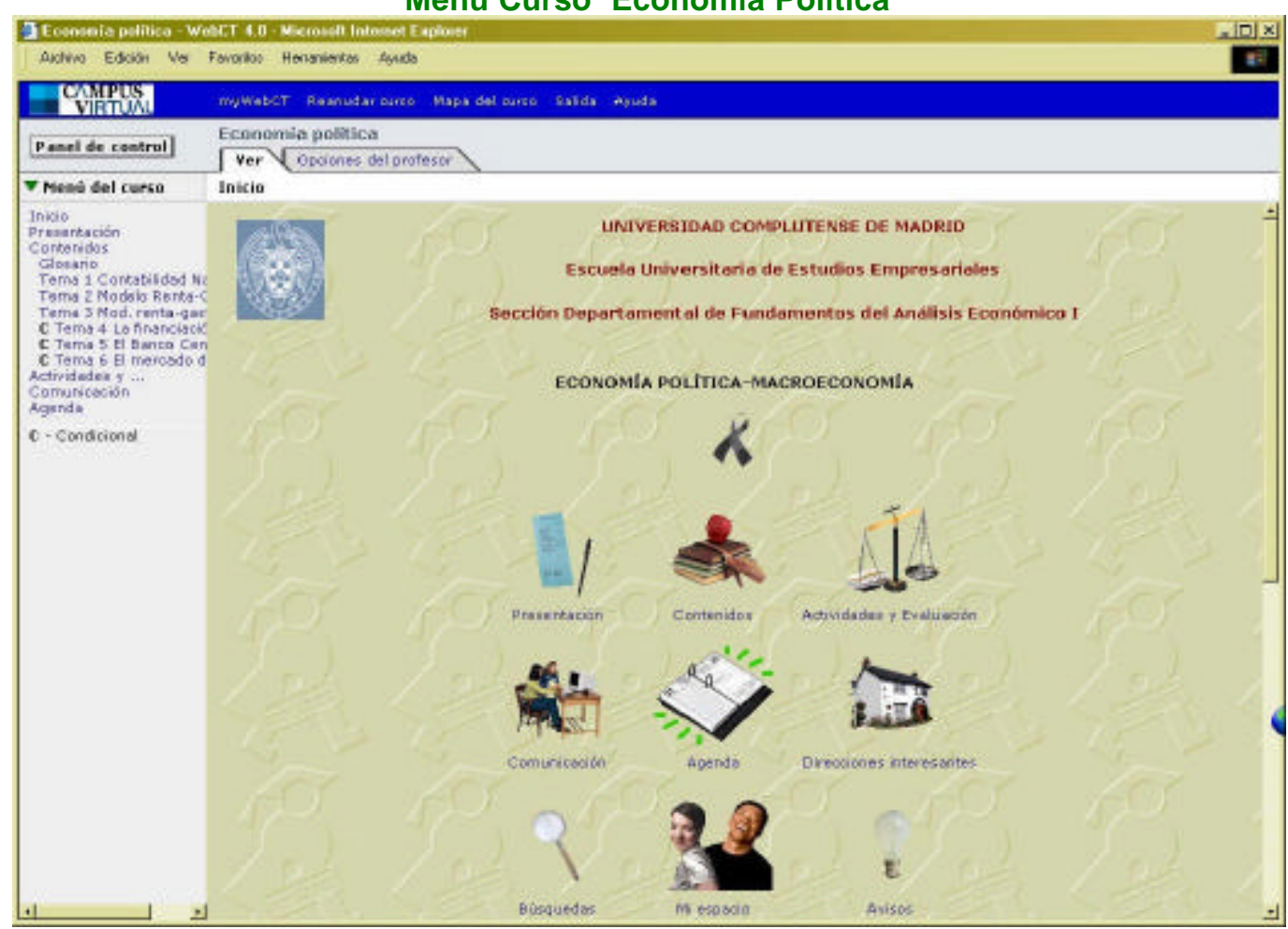


Crucigrama electrónico Economía Política

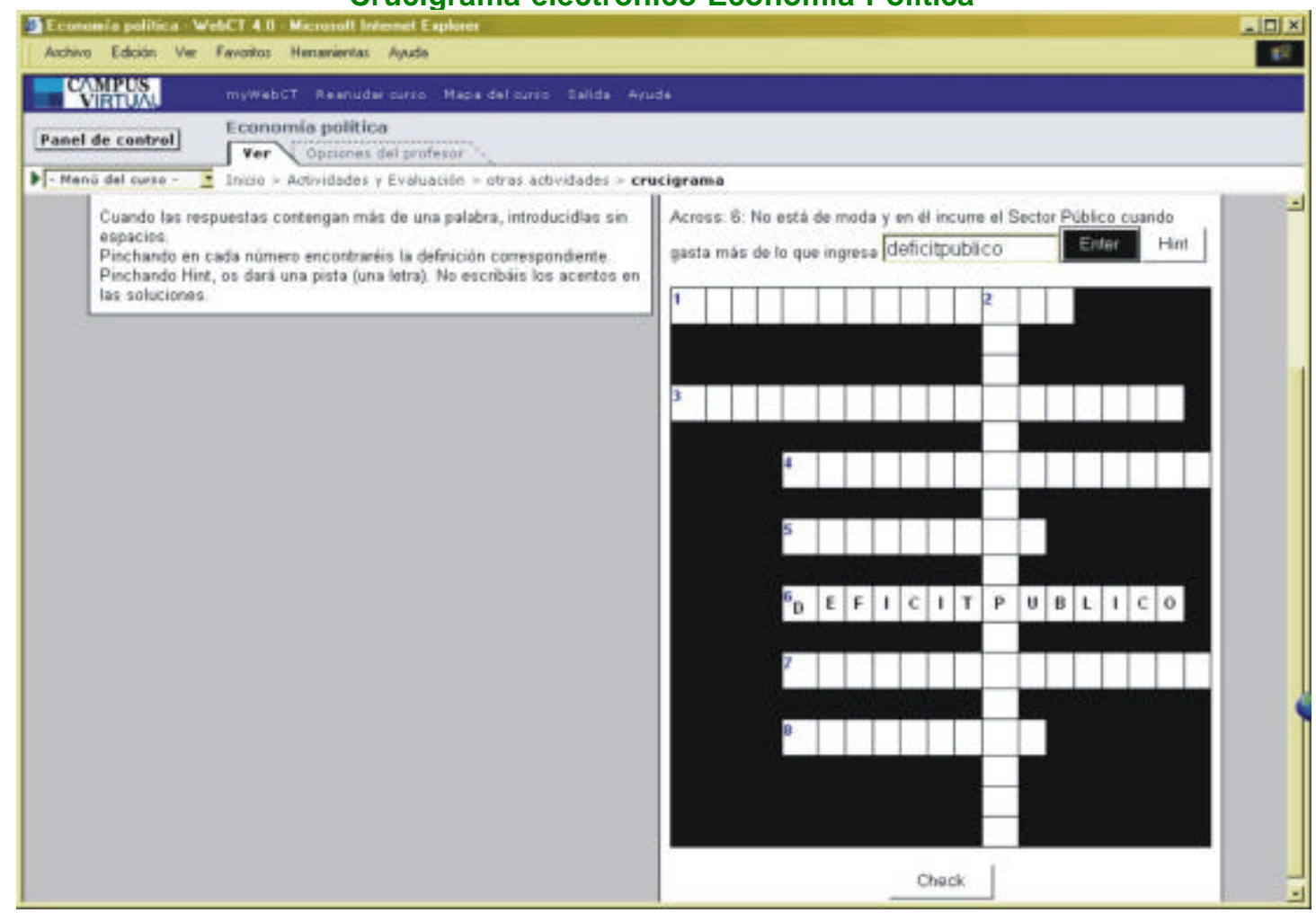

Foro de debate Microeconomía

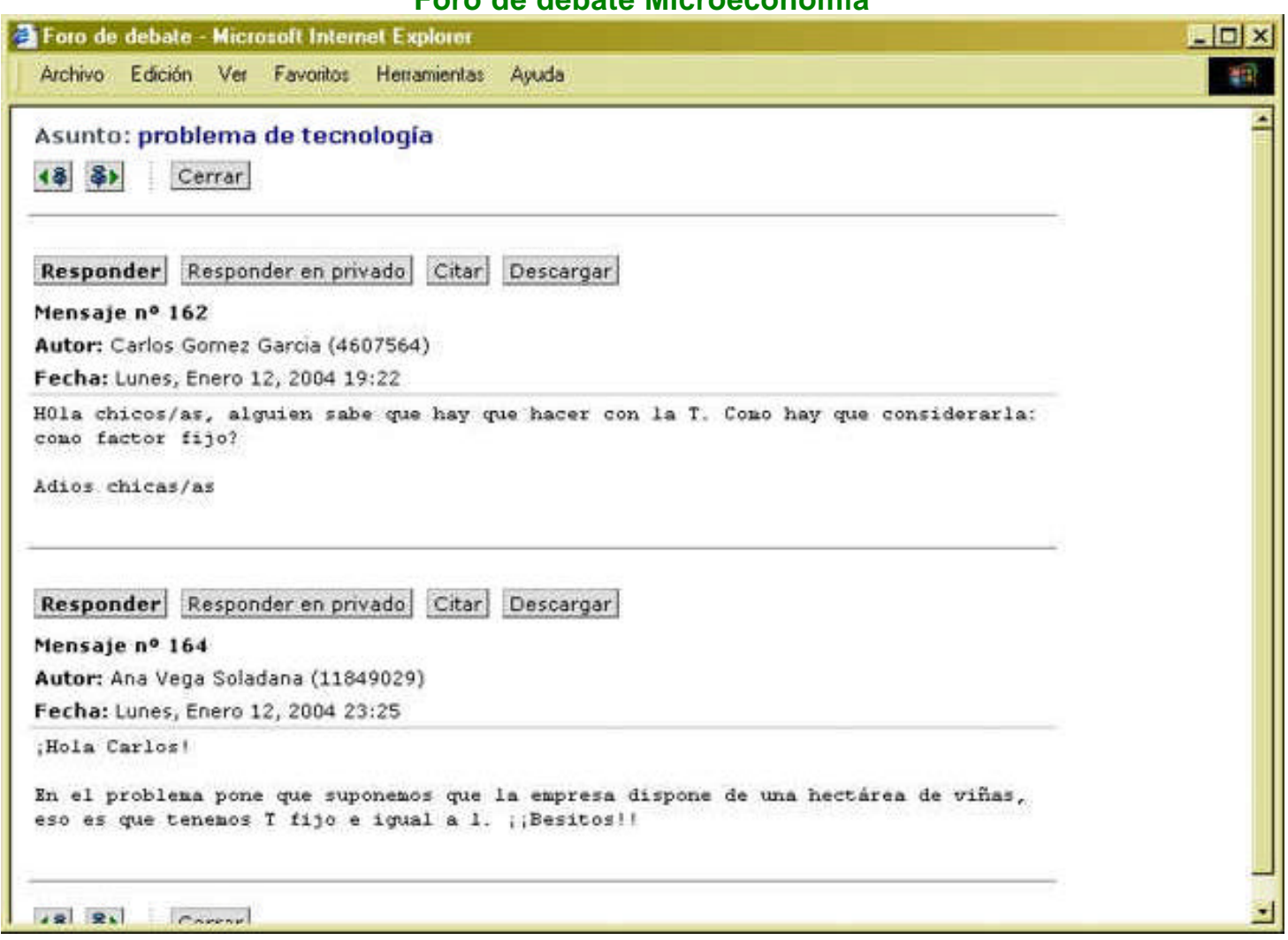




\section{Fonst}

\section{Módulo de Contenidos de Economía Política}

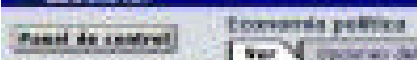

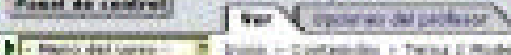

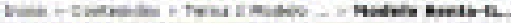

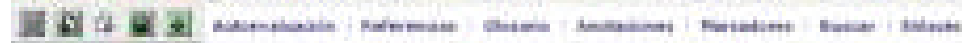

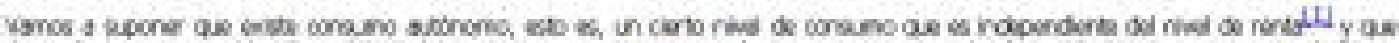

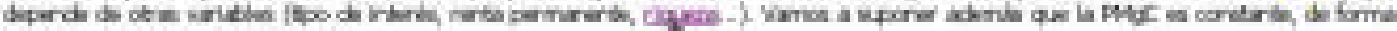

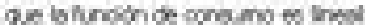

$$
C=E+c i j m i n
$$

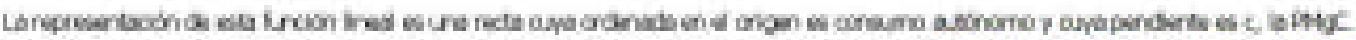

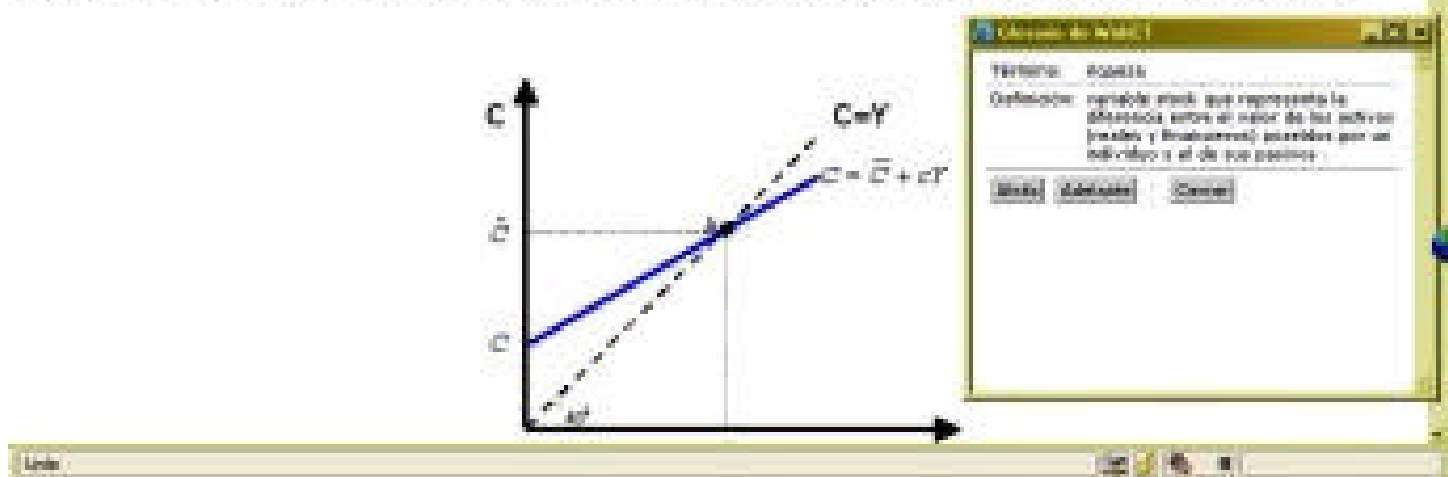

\section{Actividades Microeconomía II}

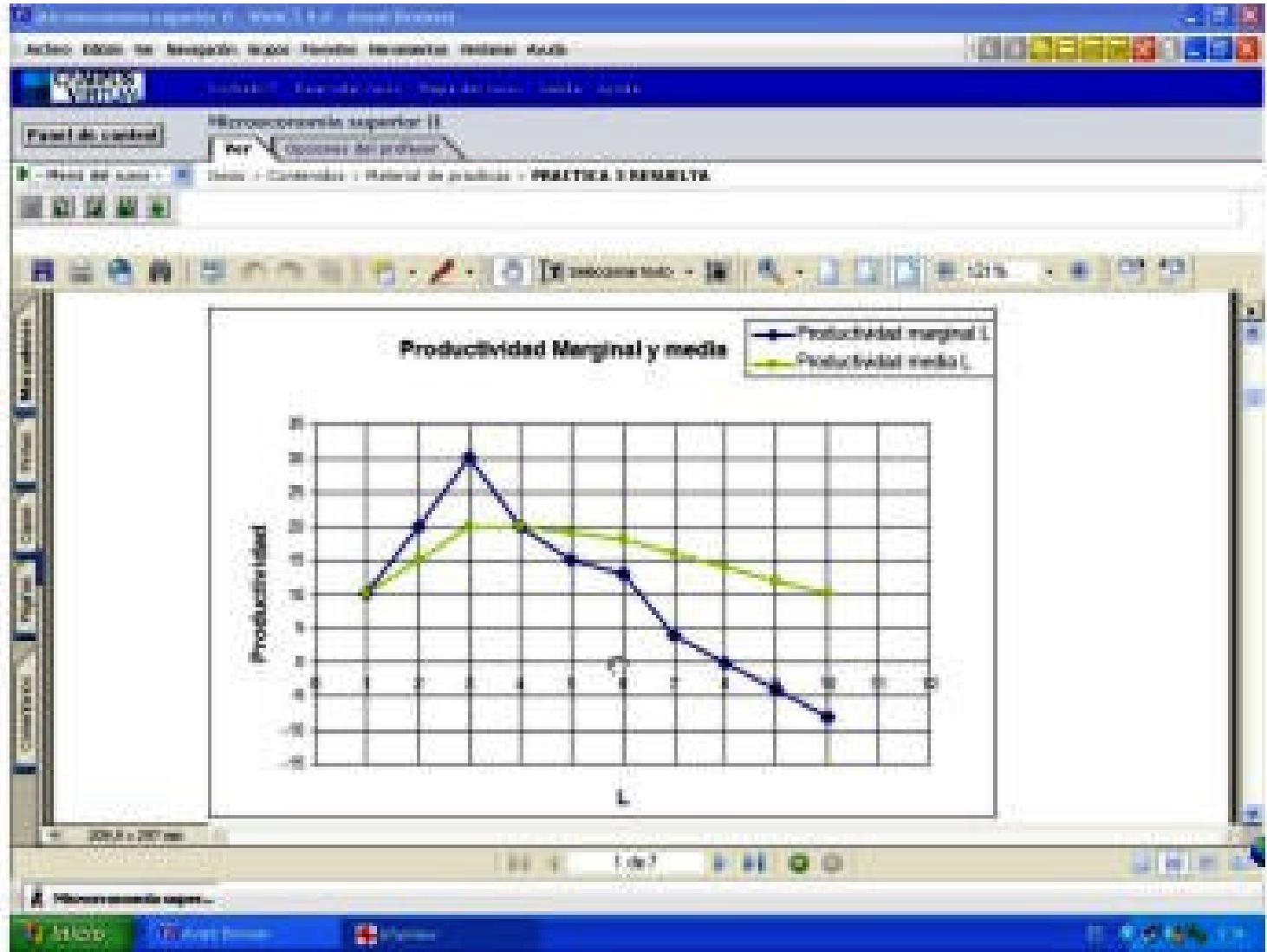


Módulo de contenidos Microeconomía II

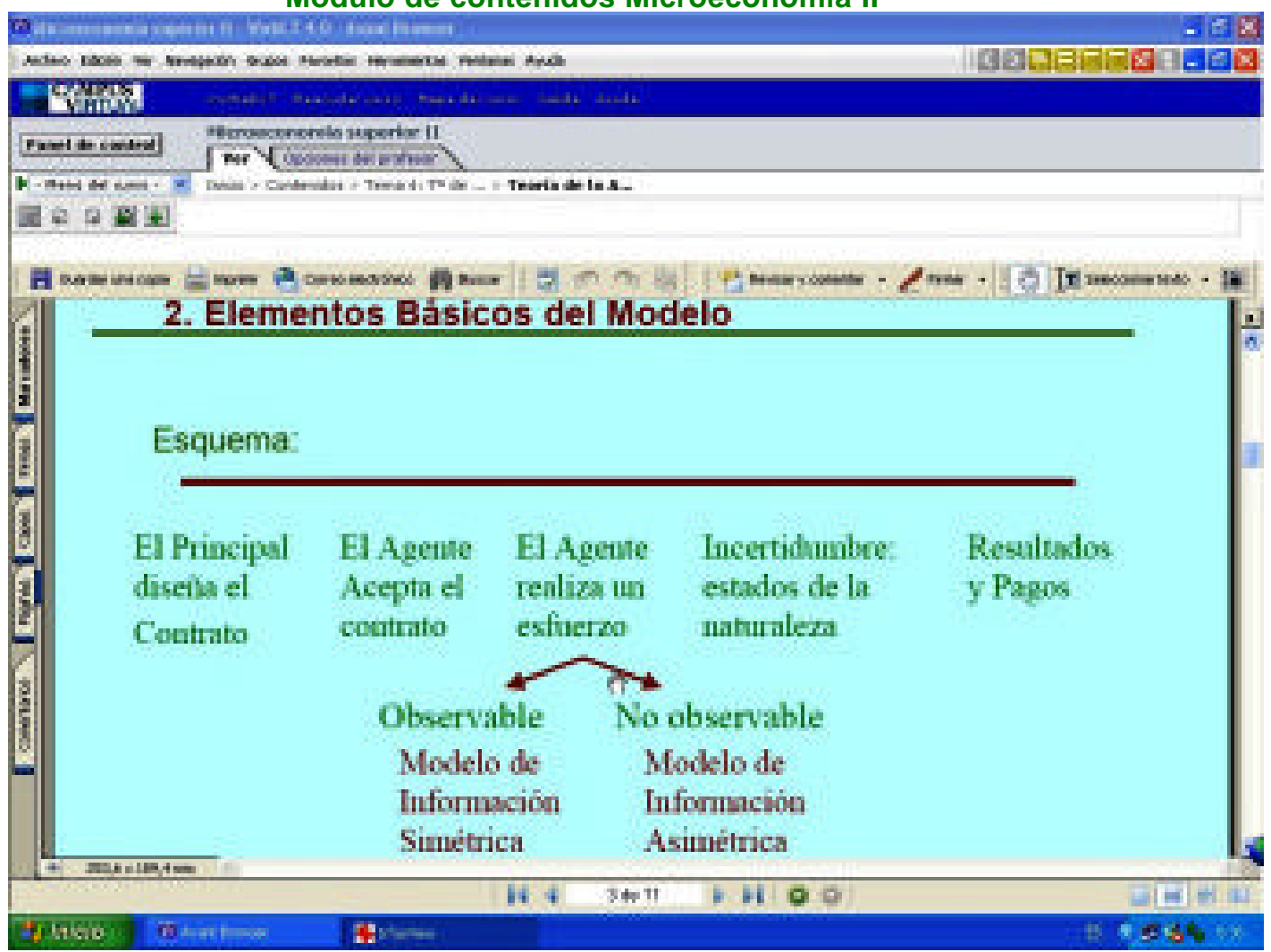

Aún asumiendo la osadía que supone valorar nuestra experiencia con la información disponible, sí podemos realizar un análisis muy preliminar.

Desde el punto de vista cualitativo, y a modo de resumen, la participación en esta experiencia está suponiendo (a) importantes costes en términos de dedicación y de adaptación técnico-pedagógica para el docente, (b) costes de adaptación y formación al nuevo modo de aprendizaje para los alumnos y (c) costes de tipo organizativo y económico para la institución.

Sin embargo, son muchos los aspectos positivos. En primer lugar, la respuesta por parte de los alumnos está siendo favorable en cuanto a participación, si bien hay que tener en cuenta que se trata de grupos de alumnos motivados a priori, y que han revelado su deseo de participar activamente en la iniciativa. En segundo lugar, la satisfacción de los alumnos al descubrir las posibilidades que les ofrece la nueva estrategia de aprendizaje: disponibilidad de materiales didácticos fiables y de instrumentos de autoevaluación, posibilidad de comunicarse de forma fluida con el profesor y el resto de los alumnos a través de los foros y el correo electrónico, la generación de soluciones cooperativas para los diferentes problemas o dudas, la tutorización personalizada y el seguimiento constante de la progresión del alumno por parte del profesor, la inclusión de elementos de evaluación continua que se han tomado en cuenta para la calificación final de las asignaturas. En tercer lugar, las mejoras en la gestión del curso derivadas de las herramientas incorporadas en la plataforma. Por último, la percepción por parte de los profesores de una mayor y más flexible comunicación con los alumnos.

Desde el punto de vista cuantitativo, se han realizado encuestas de satisfacción que permiten una primera valoración de la iniciativa. Si bien una evaluación más objetiva y global de esta experiencia será posible cuando se disponga de un volumen de información estadísticamente significativo, a continuación se presentan los resultados obtenidos en las encuestas realizadas, a instancias de la Unidad de Apoyo 
Tecnológico a la Docencia (UATD), a los alumnos de Microeconomía Intermedia de la Diplomatura de Ciencias Empresariales, impartida durante el primer cuatrimestre del curso 2003-04.

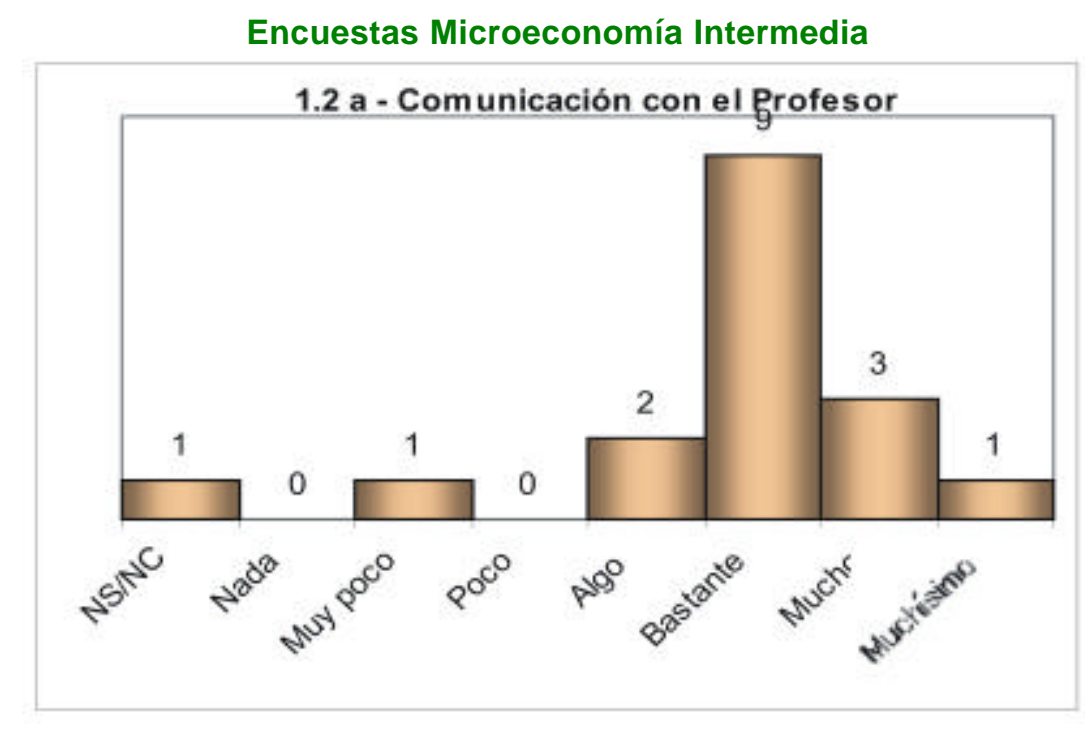

\section{Encuestas Microeconomía Intermedia}

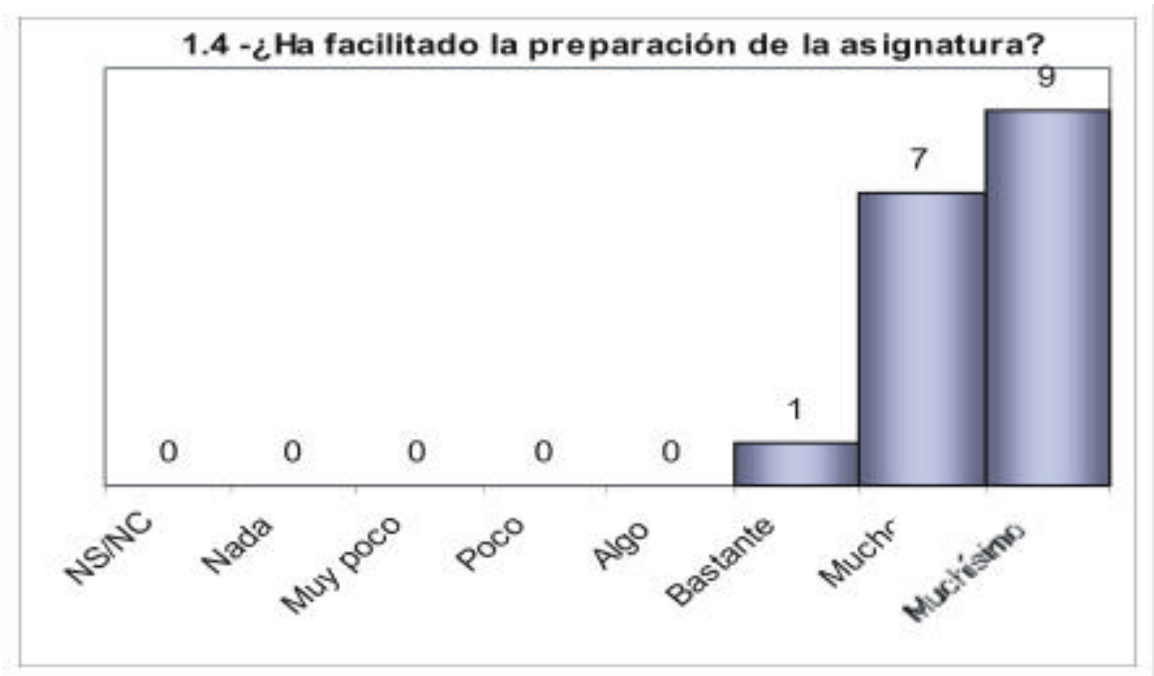

\section{Encuestas Microeconomía Intermedia}

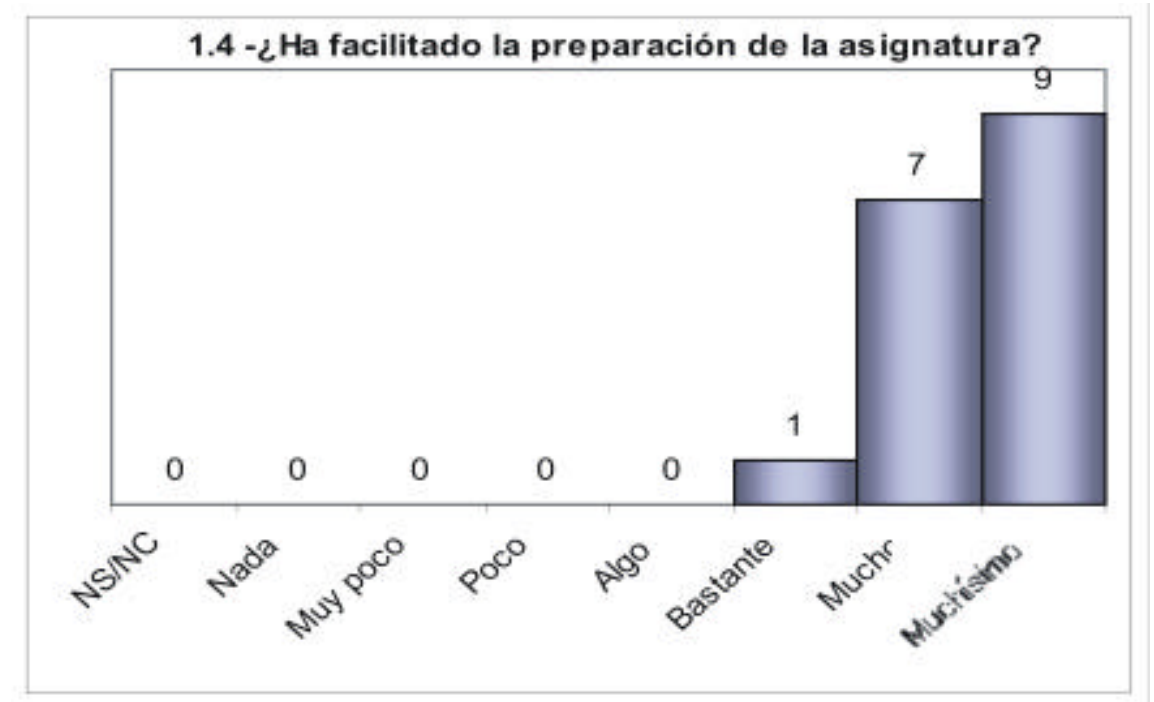


Encuestas Microeconomía Intermedia

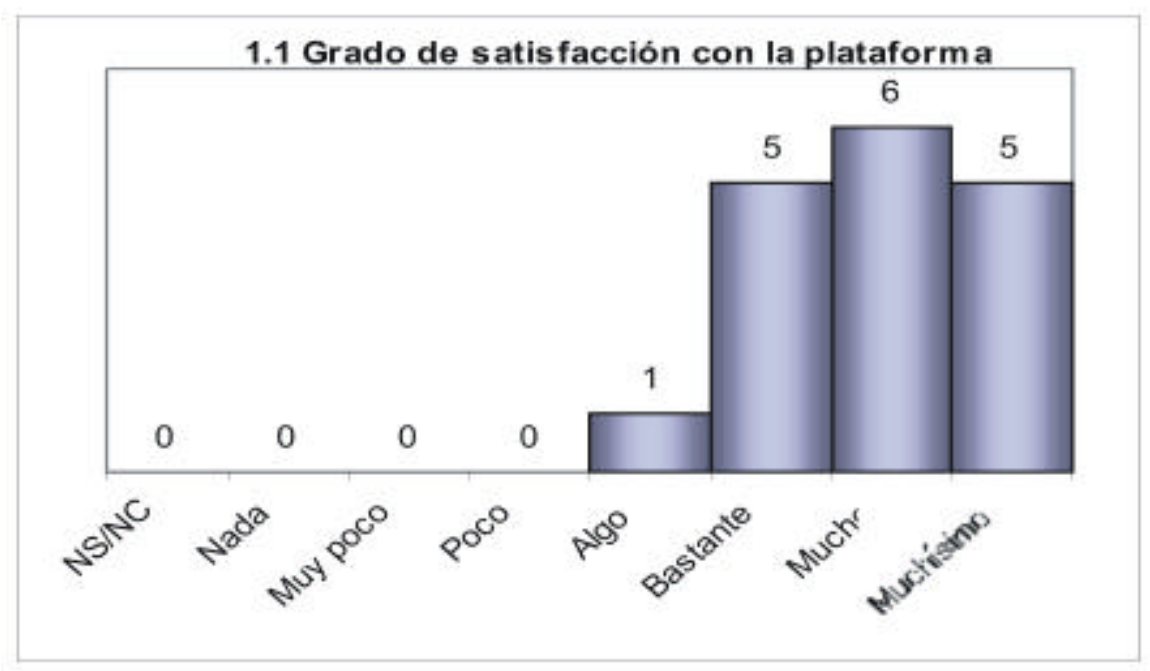

Encuestas Microeconomía Intermedia

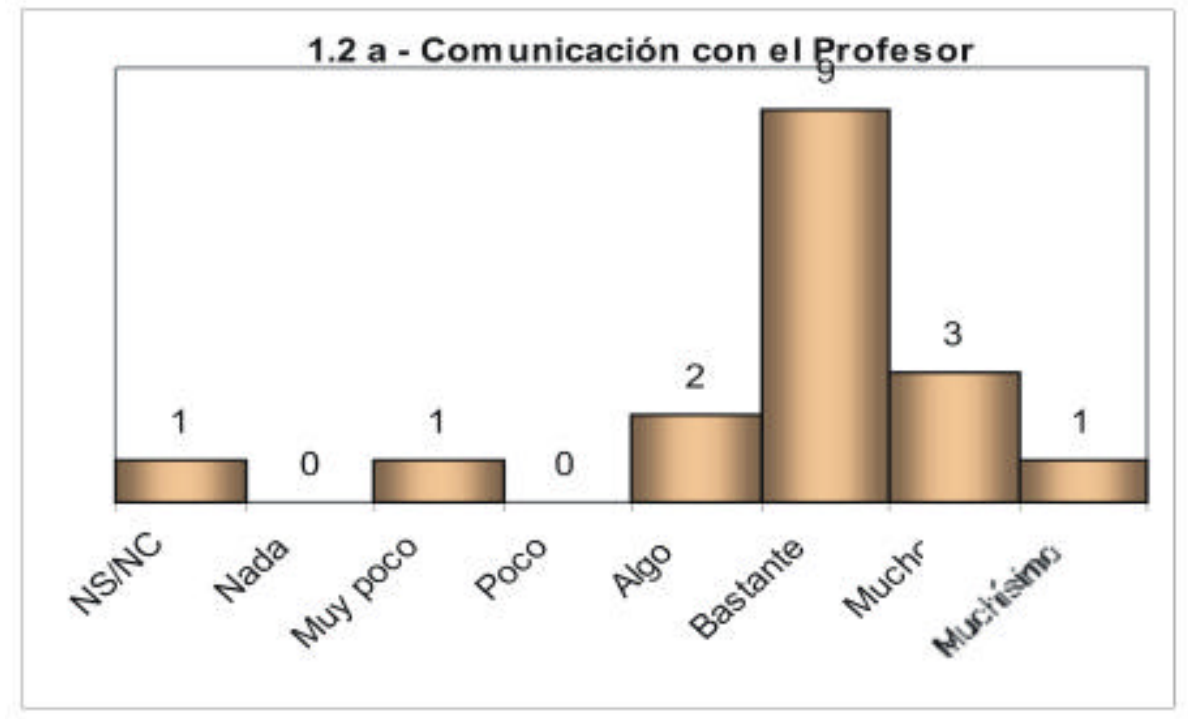

\section{EL FUTURO EN EL EEES}

Las acciones presentadas, proyectos de innovación educativa e incorporación al campus virtual, son las primeras iniciativas realizadas en el marco de una estrategia de proyección futura para la mejora en la didáctica de la enseñanza de educación superior en Teoría Económica, dentro del Departamento de Fundamentos del Análisis Económico I de la UCM.

El destinatario de tales acciones es el conjunto del poceso educativo y todos sus integrantes, alumnos y docentes, y ello porque el éxito de la acción docente no es responsabilidad exclusiva del alumno, ni se deriva únicamente del grado de esfuerzo de éste. No podemos ignorar la responsabilidad social de los docentes y las instituciones educativas en la búsqueda de una formación superior de calidad.

Desde esta óptica, nos proponemos continuar la línea de mejora docente emprendida en varios aspectos fundamentales: (1) Incorporando nuevas asignaturas al campo virtual y mejorando las ya implantadas durante este curso (2) generando para el equipo docente un mecanismo corrector de la propia 
acción didáctica a partir de los feed-back de información y el tratamiento estadístico de ésta, (3) aprovechando las posibilidades de las herramientas del Campus Virtual para profundizar el seguimiento individualizado de los estudiantes que generalice una evaluación continua de cada uno de nuestros alumnos y que les motive significativamente, (4) perfeccionando el material didáctico generado.

Los satisfactorios resultados obtenidos hasta el momento en las acciones emprendidas y la decidida apuesta por una docencia de calidad del grupo de profesores, nos animan a proseguir avanzando en la línea descrita: poner la tecnología digital al servicio de una estrategia didáctica orientada a la mejora en la calidad y a la adaptación de los modos de enseñanza-aprendizaje al futuro EEES.

\section{BIBLIOGRAFIA}

ÁREA MoreiRA, M, (2003): "De los webs educativos al material didáctico web". Comunicación y Pedagogía, n $188, p p 32-38$

ÁREA MOREIRA, M. (2002): "Problemas y retos educativos ante las tecnologías digitales en la sociedad de la Información". Quadernsdigitals ํo 28.

Área MOREIRA, M. (2001): "¿Hacia un futuro imperfecto? Pensar la educación en la sociedad de la Información" en Educar en la sociedad de la Información. Bilbao: Desclée de Brouwer

AVIRAM, R. (2002): “¿Conseguirá la educación domesticar a las TIC?” II Congreso Europeo de Tecnología de la Información. Barcelona 2002.

BARROSO OSUNA, J. (2003): "Las Nuevas, Tecnologías de la Información y Comunicación y la Formación del Profesorado Universitario". III Congreso Internacional Virtual de Educación. Cibereduca.com.

Cabero Almenara, J. (2003): “Replanteando la Tecnología Educativa”, Comunicar, (21), pp 23-30.

Cabero Almenara, J. et al. (2003): "Las Nuevas Tecnologías en la Actividad Universitaria". Píxel-Bit. Revista de Medios y Educación (20) pp 81-100.

CABERo AlmenARA, J (2003): "La galaxia digital y la educación: los nuevos entornos de aprendizaje”. En AGUADED, J.I.: Luces en el laberinto audiovisual. Grupo Comunicar, 102-121.

CABero Almenara, J. (2003): "El rol del profesor ante las Tecnologías de la Información y la Comunicación". Jornadas de Formación. ."Nuevos retos en la formación del profesorado" Centros de Profesores y Recursos de Talarrubias (Junta de Extremadura).

CERF, V. y SCHUTZ, C. (2002) "Enseñanza en el 2025: la transformación de la educación y la tecnología". En "2020 Visions, Transforming Education and Training Through Advanced Technologies. Secretarías de Comercio y Educación de los Estados Unidos. Eduteka.

MICHAVILA, F. Y otros (2003) "La tutoría y los nuevos modos de aprendizaje en la Universidad" Cátedra UNESCO de Gestión y Política Universitaria. UPM Madrid. 2003.

GISBERT Cervera, M.(2000): "El profesor del siglo XXI: de transmisor de contenidos a guía del ciberespacio". En CABERO, J. y Otros (Coords): Y continuamos avanzando. Las nuevas Tecnologías para la mejora educativa. Sevilla, Kronos, 315-331. 
HUANG, A. (1996-97): "Challenges and opportunities of online education". Journal Educational Technology Systems (25), 3, pp 229-247.

YANES GONZALEZ, J y ÁREA MOREIRA, M. (1998): "El final de las certezas. La formación del profesorado ante la cultura digital”. Píxel-Bit. Revista de Educación y Medios, ํㅡ 10

Del Val SegarR, M. (2003) "Apuntes en red, un elemento de mejora de la docencia". International Conference on Network Universities and e-Learning. Valencia. Mayo 2003. 


\title{
Contactar
}

Revista lberoamericana de Educación

\author{
Principal OEI
}

